\title{
Application of System Dynamic Model for Policy Evaluation on Welfare and State-Public Service Aspect of Navy Personnel
}

\author{
${ }^{1}$ Sukmo Hadi Nugroho, ${ }^{2}$ Kazan Gunawan and ${ }^{1}$ R. Madhakomala \\ ${ }^{1}$ Jakarta State University (UNJ), Jakarta, Indonesia \\ ${ }^{2}$ Esa Unggul University, Jakarta, Indonesia
}

\begin{abstract}
The aspect of the Navy personnel welfare and the aspect of state-public service by the Navy personnel are significant aspects which affecting the performance allowance policy. However, the application of performance allowance is not yet fully based on the achievement, workload and occupational risk which is the responsibility of the Navy personnel. This study aims to evaluate the performance allowance policy by assessing the welfare aspects and state-public services of Navy personnel. The methods of policy evaluation in this research usea model of the system dynamic method development. Identification of variables on the aspects of welfare and public service has been done including the relationship of interaction between aspects as a system. The output of the policy evaluation model is a score or the evaluation index of each of the assessed variables. The index of policy evaluation serves as an indicator indicating that the aspect variable needs to be evaluated according to the value of the conversion index and the strategic meaning obtained. Next policy scenarios are simulated on the model. Based on the evaluation and the results of the analysis conducted on the scenarios, the score of evaluation index of the policy is: evaluation score: performance allowances of Navy personnel: 8.31 (height; warning), Navy personnel welfare aspect: 8.20 (high; warning), professional income of Navy personnel: 7, 51 (high, warning), social status of Navy personnel: 6.09 (medium; moderate), State and public service aspects: 8.32 (high; warning), Navy personnel workload: 9.22 (very high, alert ), risk of assignment: 8.99 (high, warning).
\end{abstract}

$\underline{\text { Key words: System dynamic model, Navy personnel welfare, state and public servic, index, policy, relationship }}$

\section{INTRODUCTION}

The development of Indonesia Navy posture is essentially oriented towards the achievement of the main task of the Navy in order to support the national interest. The tasks of the Navy in the future will still be faced with limited defense budget and limited human resources on the other hand the rapidly changing strategic environment in global competition will further add to the complexity of the problem, mainly in law enforcement and security efforts and in maintaining the sovereignty of the Unitary State of the Republic Indonesia.

The development of the human resources force of the Navy and the modernization of weapons systems should be implemented in a planned, gradual and sustainable manner by keeping in mind the state capability or budget available. The priority of the object of strength development, among others, focuses on the field of organization, Human Resources Development (HRD), material of defense equipment bases and stock materials.

Especially for the development of $\mathrm{HRD}$, the Navy has implemented various policies in the field of performance management to improve the professionalism of personnel, one of them is by giving performance allowance. The policy is in line with the government's commitment as stated in the 2008 National Defense white paper mentioned that the increase of professionalism cannot be separated from the improvement of welfare through the adequacy of salaries, the provision of residential facilities, health insurance, educational improvement and the preparation of the term life insurance scheme. Improving the welfare of Navy personnel is the task of the government to keep the professionality of the Navy.

Based on the Regulation of the Minister of Administrative Reform and Bureaucracy Reform No. 63 of 2011 on Guidelines for Structuring the Performance System of Civil Servant Performance, it can be explained that performance allowance is a function of the successful implementation of bureaucratic reform. Employee performance allowance is given based on the performance achieved by an individual employee. The performance of each individual employee must be in line with the performance to be achieved by the agency.

Provision of performance allowances or remuneration or compensation has a positive impact on the achievement of job satisfaction, performance improvement and decreased absenteeism. Compensation can improve

Corresponding Author: Sukmo Hadi Nugroho, Jakarta State University (UNJ), Jakarta, Indonesia 
job satisfaction and employee performance. Remuneration can improve employee performance, so, it can support the success of the bureaucratic reform program. Conceptually, giving performance allowance is actually one of the right steps to improve the performance of Navy personnel.

This research will evaluate the policy of determining the performance allowance through system dynamic methods approach, so that, it can produce novelty model. The focus of the research is to evaluate the policy of determining the performance allowance as one of the human resource development models in order to improve the performance and professionalism as well as the welfare of the Navy personnel. This needs to be done considering the decision in determining the policy of giving performance allowance in the Navy is a government policy that aims to improve the welfare of personnel in a sustainable or policy for sustainable welfare.

The purpose of this study is to make a comprehensive evaluation of the performance policy scenarios of performance alignment within the Navy by considering the interaction between influential variables within it as a dynamic system, so that, the selected policy can be sustainable to be adapted as input for the improvement of the Presidential Regulation No. 87 the Year 2015 on employee performance allowance in the Navy Institution, so in the presidential regulation is set the number of performance allowances are given based on achievement, burden and level of work risk. Evaluation of the provision of performance allowances within the Navy will give birth to a recommendation related to the improvement of performance allowance system in order to improve the quality of human resources that is adjusted to the dynamics of the system and the development of the Navy sustainable. In detail, the focus of this study can be reviewed from five sub-focus as follows.

Identify the factors that influence the program and the implementation of performance allowance policy within the Navy as a system that interacts. Preparation of program evaluation model of the system of giving performance allowances in the environment of the Navy sustainable. Preparing performance policy scenarios in the Navy's performance environment along with analyzing the impacts and effects of those scenarios on aspects of:

- The welfare of Navy personnel

- State and public services of Navy personnel

Comprehensive analysis and evaluation of policy scenarios applied to the system of determining performance allowances within the Navy. Determination of the best sustainable policies on the determination of performance allowances based on a thorough evaluation of the impact of factors and criteria as an interacting system.
Based on this it is necessary to analyze, study and in-depth research on how the application of the policy of giving performance allowance for Navy personnel in naval unit work and its impact to the welfare of Navy personnel, and state-public service. In-depth analysis, study and research are conducted by considering the dynamics of the upcoming system, so as to obtain the results and the real impact of the best policy evaluation in the field of human resources, so that, it can be used to improve the performance allowance system within the Navy.

\section{MATERIALS AND METHODS}

The welfare of Navy personnel: The term welfare is an ambiguous meaning, it is used to refer to the well-being of individuals and to systems designed to be given to society (Martinez-Moyano et al., 2008). At a certain level, the function of social welfare is to provide the same social order for each set of orders on the individual. Provisions in welfare include health care, housing, social security, education and social work (Sandfort, 1999). In the context of the welfare of TNI AL soldiers, the happiness, prosperity, satisfaction, quality of life of Navy soldiers can be achieved as a reward for performance in order to serve the country and nation. There are many indicators of welfare that can be achieved by a Navy personnel. The researcher identified, among others.

Salary and income/take-home pay is enough. Gaining clothing and food and adequate housing, so that, soldiers can live safely no need to feel anxious in the face of life in the future. Obtain health facilities including medical personnel, medicines, hospitals and health centers of Navy personnel with adequate equipment and personnel at a reasonable cost for the purchasing power of Navy personnel. Gain the education of both the soldier himself and his family at all levels of either general or professional education. Getting old age guarantees, so, the soldier feels calm and secure in facing his old age or when he can not earn a living. Getting adequate means of transportation, so that, the Navy personnel easily, quickly and cheaply to move in the face of all its affairs. Getting job descriptions according to their desires and abilities. Gain opportunities to develop and enjoy culture, perfecting the life of religious morals and intellectual life. Getting the possibility to rest or leave and enjoy entertainment.

State and public service of Navy personnel: The Law Regulation No. 25 The year 2009 on Public Service defines public services as activities or series of activities in the context of fulfilling the needs of services in accordance with legislation for every citizen and residents of goods, services and/or administrative services provided by public service providers. Public services are prepared and carried out by public service providers which are the work 
units of public service providers residing in the state institutions, corporations and independent institutions established by the law (Hasenfeld, 1993).

The Indonesian Navy is one of the institution of state organizing state and public service. Public services carried out by the Navy as stipulated in Law No. 34 of 2004 on the Indonesian Navy which affirms the main task of the Indonesian is to carry out Military Operations for the War (OMP) and Military Operations Other Than War (OMSP) to protect the entire nation and the entire spill of Indonesia from the threat and disruption of the integrity of the nation and state.

Based on the decision of Indonesian Navy Commander No.: Kep/1035/XII/2014 dated 31 December 2014 on road map of bureaucratic reform of Indonesian Navy, the Year 2015-2019, public service carried out by the Navy focused on activities.

Operation of PPRC (The Quick Reaction Safety Forces) and Operation of PPRC (The Quick Reaction Security of Support Force).

Border security operations and outlying islands, procurement of goods and services, public health services, optimizing the active role of the TNI in the life of nation and state to assist the acceleration of national development.

Citizens are very hopeful of public services made by the state apparatus including the Navy personnel. Good public services will increase public confidence. According to the researchers, there are several important elements in the process of public service in general which must be considered, namely. The service provider is a party that can provide a certain service to the public, either in the form of provision and delivery of goods or services.

Recipients of services are those who are referred to as consumers or customers in this society/public who receive various services from service providers government apparatus. Type of service is a service that can be provided by service providers (government apparatus) to parties that need service (public). Satisfaction of public/society in giving service provider service must refer to the main purpose of service that is public satisfaction or society. This is very important because the level of satisfaction obtained by the public/community is usually very closely related to the quality standards of goods and or services that they enjoy. This should also apply to public service policies by members of the Navy. There are some basic points in the delivery of public services by government officials to be considered (Bryson, 1995) include.

Empathy with the community: Government apparatus including the Navy personnel serving the affairs of the service provider agencies should be able to empathize, concern and be sincere with the public or the public of the service user.

Prohibition of procedures: Public service procedures should be designed as short as possible, so, the concept of a one-stop shop is really implemented.

Clarity of public service procedures: The service procedure should be designed as simply as possible and communicated to the public service users.

Minimization of service requirements: Requirements in administering services should be limited as little as possible and as much as is absolutely necessary.

Clarity of authority: The authority of the state apparatus serving the community of service users should be formulated as clearly as possible by creating a task chart and distribution of authority.

Transparency of costs: The service charge should be set as minimum and as transparent as possible.

A certainty of schedule and duration of service: Schedule and duration of service must also be sure, so that, people have a clear picture and not restless.

Clarity of the rights and obligations of state apparatuses including the Navy personnel and the public or the public as customers. Rights and obligations both for the state apparatus and for the community as customers must be clearly defined and supplemented by sanctions and provisions of indemnification.

The effectiveness of complaint handling: Good service wherever possible should avoid complaints. However, if a complaint arises, a mechanism must be designed to ensure that complaints are handled effectively, so that, the issues can be resolved promptly (Thornhill, 2009).

System dynamic approach: The system dynamic model is a comprehensive policy evaluation model that views each issue holistically, systematically and integratively. By using systemdynamic model, expected process and problem-solving result expected to be executed effectively and efficient (Forrester, 1997).

This study has many literatures to support the research such as: a new method for modeling system dynamics (Youssefi et al., 2011), system dynamics-based modeling and analysis of greening the construction industry supply chain (Sundarakani et al., 2014). The politics of public policy and problems of implementation in Africa (Imurana et al., 2014), leadership, governance 
and public policy implementation competencies in the Broader Public Sector (Muhammad, 2014), establishing the location of Naval base using fuzzy MCDM and covering technique methods (Suharyo et al., 2017), applied of impressed current protection design network at Naval base (Ahmadi et al., 2017). There are seven interlocking problem-solving steps forming a loop in the dynamic system methodology (Stermann 2000):

- Identification and definition of the problem

- Conceptualization of the system

- Model formulation

- Simulation and validation of models

- Policy analysis and improvement

- Understand and distinguish

- Implementation of policies

The loop shows that each subsystem is interconnected and continuously connected never ends. This indicates that every problem has an ever-evolving system dynamics (Tsolakis and Snai, 2017).

System dynamic model variables: Some system dynamic model variables can be seen in Fig. 1 .

Level variable: In Fig. 1, it can be explained that the level variable represents the accumulation or integration of a stream over time. In real systems, there are basically two types of levels: the physical subsystem or the information subsystem. The physical subsystem is concerned with the flow of physical resources such as materials, labor, money, orders and so on. The information subsystem is concerned with the flow of information in systems connecting physical entities (Stermann, 2000).

Rate variable: In Fig. 1, it can be further explained that the rate variable in the system is basically a decision variable that is governed by one or more policy structures. Rate determines the incoming/outflow flow from/towards a level. The decision taken is to determine the magnitude of the effect of a rate at a time on the level and information about the system. A rate is measured by policies translated in the form of the flow of information that affects the variable rate (Stermann, 2000) (Fig. 2 and 3).

Auxiliary variable: In Fig. 1 , it can be explained that auxiliary variables are complementary variables that theoretically represent a better and clear policy structure. This variable is an additional variable that can not be eliminated in the policy structure illustrated in the model (Stermann, 2000).
System dynamic model diagram: In the development of systemdynamic model there are 2 model diagrams.

Causal loop diagram: The causal loop diagram is the disclosure of a causal relationship into a particular image language. The image language is an interconnected arrow, thus, forming a causal loop where the arrowhead reveals the cause and tip of the arrow expressing the effect. Both, the elements of cause or effect or one of them (cause or effect only) must refer to measurable circumstances both qualitatively for perceived and quantitative circumstances for actual circumstances. The process of causal loop diagrams is simple or the process of structuring is

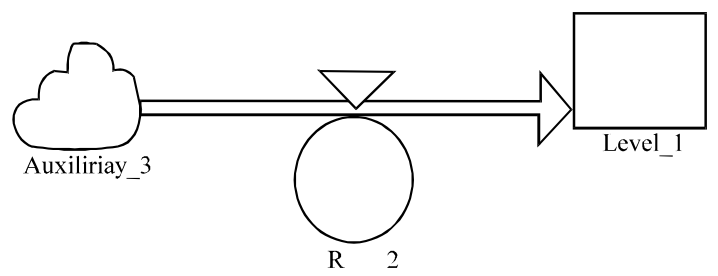

Fig. 1: Level, rate, auxiliray variable

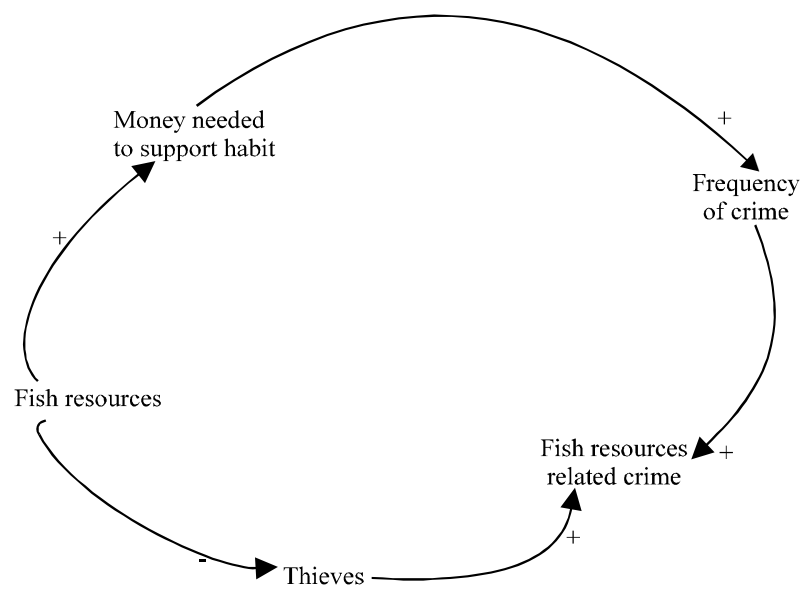

Fig. 2: Example of simple causal loop diagram

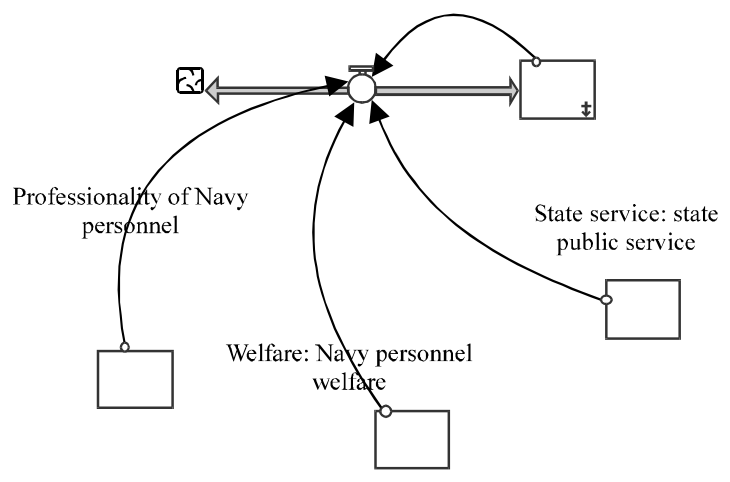

Fig. 3: Example of stock and flow diagram 
arranging the causal relationship into a closed system, resulting in loops. They can be positive or negative. Called positive, if the variable change at the beginning of the flow causes the increase of the variable value at the end of the flow. Conversely, it is called negative if changes in the variable at the beginning of the flow cause the reduced flow value (Stermann, 2000). The sample of simple causal loop diagram as follows.

Stock and flow diagram: Stock and flow diagrams represent flow structures in detail, so, it can be used to construct mathematical models. The simulation flow diagram illustrates the relationship between variables and is expressed in the form of feedback structure symbols. The sample of simple stock and flow diagram as follows.

\section{RESULTS AND DISCUSSION}

Variable identification: Based on the observation and understanding of the performance allowance system within the Navy, it can be identified that all the variables affecting the performance system of Navy personnel, which can be categorized into 3 main aspects of performance evaluation system evaluation:

- The professionallyof Navy personnel aspects

- The welfare of Navy personnelaspects

- The state public service of Navy personnel aspects

Every main aspect of performance allowances in thepolice of evaluationhas interrelated variables or criteria interacting in the system as shown in Fig. 4. Causal loop diagram model interaction between the main aspects of the performance allowance system of Navy personnel.

In this study, more details will be identified specifically on the welfare aspects and state and public service Navy personnel aspects. Based on the results of the identification of performance allowance system of the Navy personnelvariables, there are significant variables as shown in Table 1. Welfare aspects variable. State and public service aspects variable as follows:

\section{Welfare aspects variable:}

- Salary/Income

- Education

- Health

- Housing

- Social status
Table 1: Index of evaluation; Performance allowances variables Evaluation of performance

\begin{tabular}{lll} 
allowance variable & Index conversion & Strategic meaning \\
\hline Very low & $1.00-2.99$ & Very safe \\
Low & $3.00-4.99$ & Safe \\
Medium & $5.00-6.99$ & Moderate \\
High & $7.00-8.99$ & Waming \\
Very high & $9.00-10.00$ & Alert \\
\hline
\end{tabular}

- Public recognition

- Institution recognition

\section{State and public service aspectsvariable:}

- Navy main task

- Military operation/war

- Military operation/non-war

- Maritime territorial

- Public sociality

- Risk assignment

- Work load

Each variable on the aspect of welfare and public service aspect of the Navy soldiers has interrelated values and forms an interaction in the evaluation of performance allowances system.

Index of evaluation: Each variable in the evaluation of performance benefit system is assessed and scored (rating) on the dynamic system model, namely: very low, low, medium, high and very high by using parameters measurable. The evaluation index serves to show that these variables need to be given special attention in the evaluation of performance allowance systems, according to the value of the conversion index and the strategic significance of very safe, secure, moderate, warning and alert. The higher the value of the conversion index the higher the variable is evaluated. The evaluation index can be shown as follows.

The causal loop diagram model: Figure 4 shows the casual loop diagram model (Fig. 4).

Stock and flow diagram: Figure 5 shows stock and flow diagram.

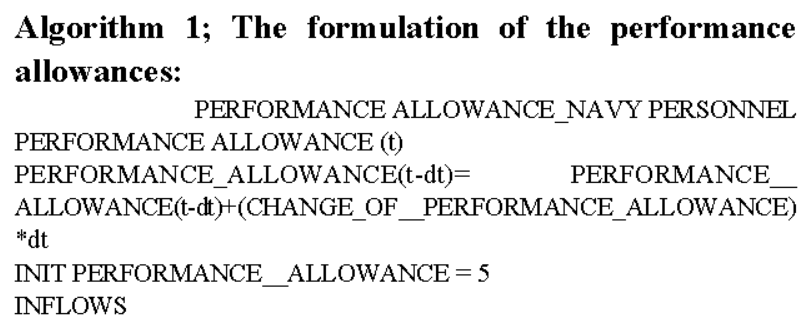

Algorithm 1; The formulation of the performance allowances: PERFORMANCE ALLOWANCE $(\mathrm{t})$ PERFORMANCE_ALLOWANCE $(\mathrm{t}-\mathrm{d} t)=\quad$ PERFORMANCE ALLOWANCE(t-dt)+(CHANGE_OF_PERFORMANCE_ALLOWANCE) $* \mathrm{dt}$

INIT PERFORMANCE_ALLOWANCE $=5$ INFLOWS 


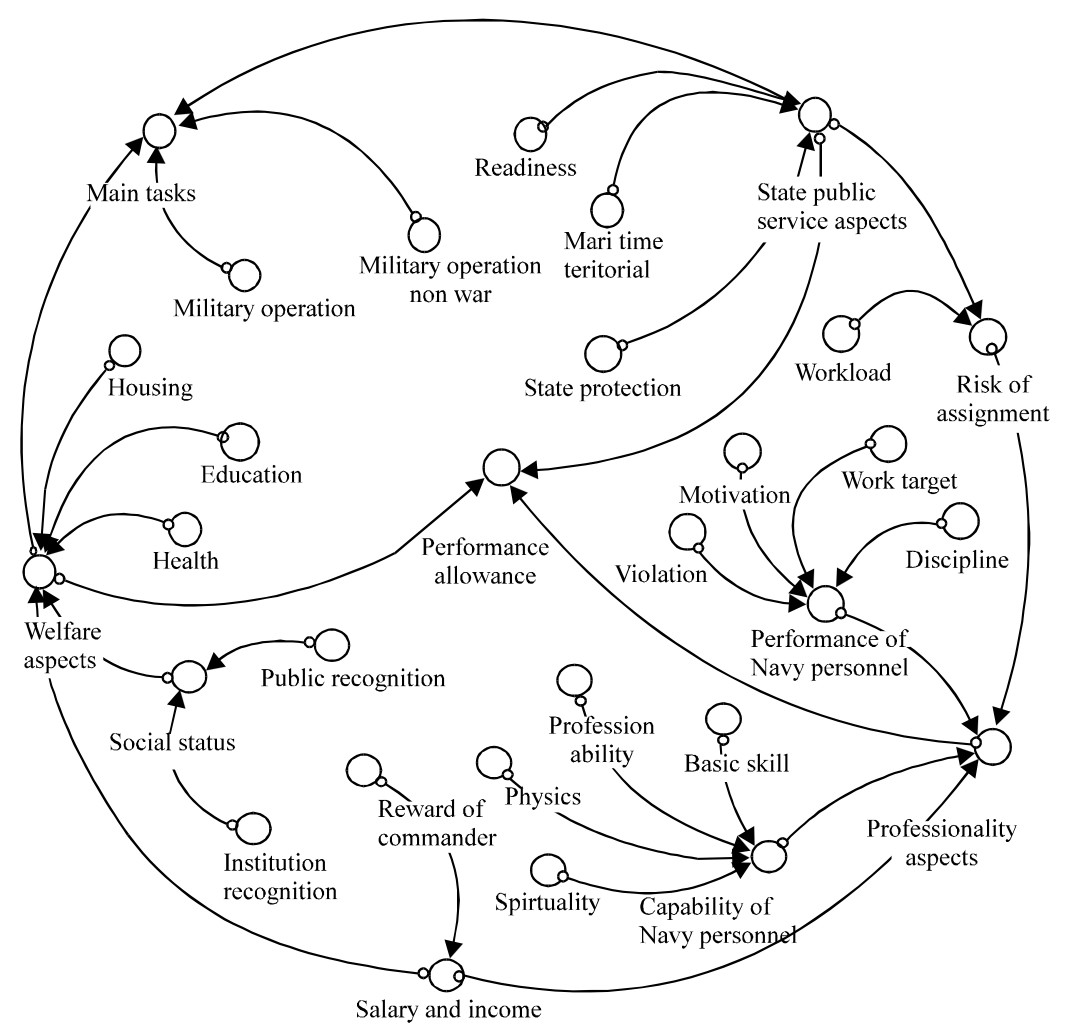

Fig. 4: Causal loop diagram of interaction model on performance allowances system

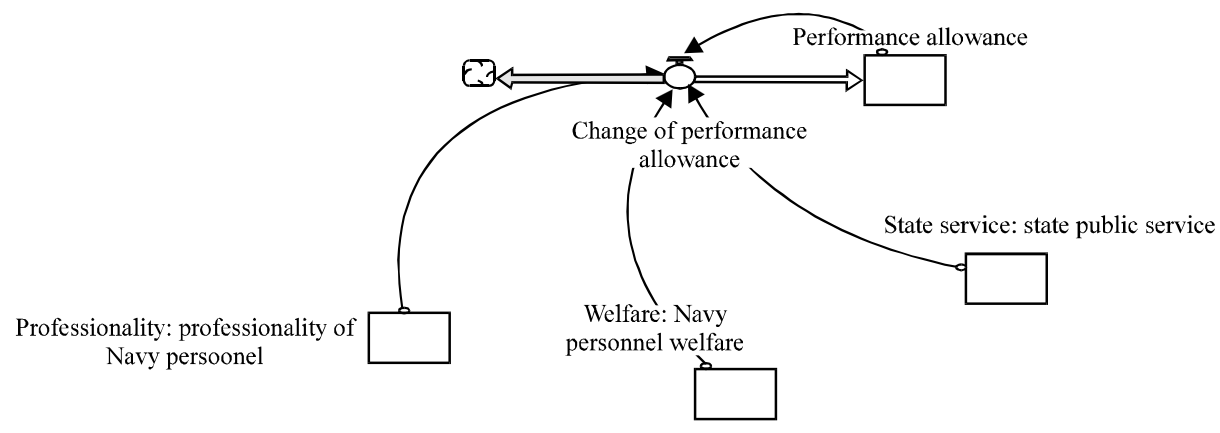

Fig. 5: Stock and flow diagram of the main aspects of the performance allowances

Welfare aspects: Figure 6 shows the stock and flow diagram.

\footnotetext{
Algorithhm 2; The formulation of welfareaspect: WELFARE ASPECTS

SOCIAL_STATUS $(t)=$ SOCIAL_STATUS $(t-d t)+($ SOCIAL_STATUS_ CHANGE)*dt

INTT SOCIAL_STATUS $=6$

INFLOWS:

SOCIAL STATUS CHANGE $=$ (SOCIAL STATUS*CHANGE OF COMMUNITY_CONDITIONS)/400

COMMUNITY RECOGNITION $=$ SOCIAL STATUS

NAVY_PERSONNEL_SERVICE $=0.6 *$ STATE_PROTECTION $+0.4^{*}$

STATE SERVICE.SOCIAL AID FOR COMMUNTTY

NAVY_PERSONNEL_READINESS $=\left(0.157^{*}\right.$ RECOGNITION_OF_
}

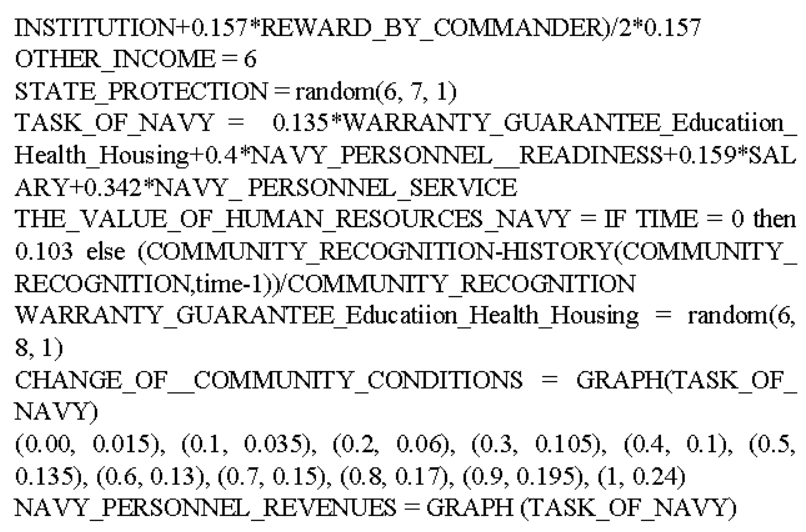


$(0.00,0.00),(0.1,0.001),(0.2,0.001),(0.3,0.002),(0.4,0.002),(0.5$, $0.003),(0.6,0.006),(0.7,0.007),(0.8,0.007),(0.9,0.008),(1,0.009)$ RECOGNITION_OF_INSTITUTION $=$ GRAPH(NAVY_PERSONNEL_ WELFARE)

$(0.00,0.135),(0.1,0.24),(0.2,0.335),(0.3,0.425),(0.4,0.525),(0.5$, $0.56),(0.6,0.6),(0.7,0.68),(0.8,0.76),(0.9,0.86),(1,0.93)$

REWARD BY_COMMANDER $=$ GRAPH(PROFESSIONALITY. CAPABIITY_OF_NAVY_PERSONNEL)

$(0.00,0.13), \overline{(0.1}, \overline{0} .175), \overline{(0.2}, 0.225),(0.3,0.245),(0.4,0.28),(0.5$, $0.315),(0.6,0.36),(0.7,0.405),(0.8,0.45),(0.9,0.695),(1,0.855)$

SALARY $=$ GR APH(THE_VALUE_OF_HUMAN_RESOURCES_NAVY)

State and public service aspect: Figure 7 shows the state and public service aspects stock and flow diagram.

Algorithm 3; The formulation of state and public service: STATE AND PUBLIC SERVICE

NAVY_PERSONNEL_WORK_LOAD (t) = NAVY_PERSONNEL_ WORK_LOAD $(\mathrm{t}-\mathrm{dt})+(\mathrm{CHANGE} \text {-OF_WORK_LOAD })^{*} \mathrm{dt}$

INIT NÄVY PERSONNEL WORK LOAD $=\overline{6}$

INFLOWS:

CHANGE_OF_WORK_LOAD $=\left(\left(0.153{ }^{*}\right.\right.$ NAVY_PERSONNEL WORK LOAD $+0.130^{*}$ MILITARY OPERATION NON WAR +0.15 1 *MILITARY_OPERATION_OF_WAR+

$0.132{ }^{*}$ OTHER ASSIGNMENTS) ${ }^{*} 0.151$ *MAIN TASKS)

STATE_PUBLIC_SERVICE $(\mathrm{t})=$ STATE_PUBLIC_SERVICE (t-dt)

$+($ CHANTGE_OF_STATE_PUBLIC_SERVICE)**dt

INIT STATE PUBLIC SERVICE $=5$

INFLOWS:

CHANGE_OF_STATE_PUBLIC_SERVICE $=\left(\left(0.153^{*} \mathrm{NAVY}\right.\right.$ PERSONNEL WORK LOAD $+0.132 *$ TERITORIAL OF MARITIME+ $0.159{ }^{*}$ NAVY_PERSONNEL_REVENUE)*3)-

STATE_PUBLIC_SERVICE+2

COMMUNITY CONFLICT $=$ random $(4,5,1)$

COMMUNITY_DEVELOPMENT $=$ random $(7,8,1)$

MILITARY_OPERATION_OF_WAR $=$ random $(8,9,1)$

MILITARY_OPERATION_NON_WAR $=$ random $(8,9,1)$

OTHER ASSIGNMENTS $=$ random $(8,9,1)$

RISK OF ASSIGNMENT $=$ STATE PUBLIC SERVICE* 1.08

SOCIAL_AID_FOR_COMMUNITY $=0.04$

TERITORIAL_OF_MARITIME $=\left(0.130^{*} \mathrm{CONFLICT}\right.$

INTEGRATION_AREA $+0.130^{*} \mathrm{COMMUNITY} C \mathrm{CONFLICT}+0.132 * \mathrm{C}$ OMMUNTTY_DEVELOPMENT)*3

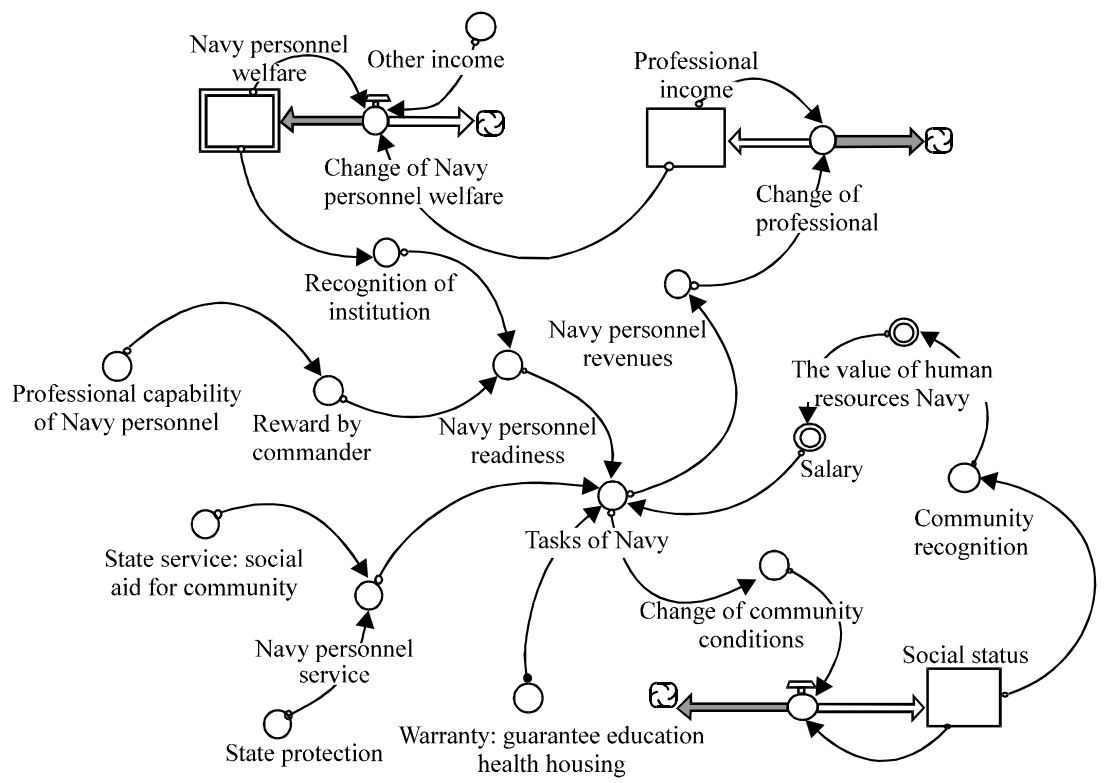

Fig. 6: Stock and flow diagram of the welfare Navy personnel aspects
CONFLICT_INTEGRATION_AREA $=$ GRAPH(SOCIAL_AD_FOR COMMUNTTY

$(0.00,0.97),(0.1,0.75),(0.2,0.62),(0.3,0.515),(0.4,0.43),(0.5,0.355)$, $(0.6,0.27),(0.7,0.21),(0.8,0.135),(0.9,0.115),(1,0.075)$

MAIN TASKS $=\quad$ GRAPH(PROFESSIONALITY.NAVY_ PERSONNEL SERVICE)

$(0.00,0.302),(0.1,0.19),(0.2,0.133),(0.3,0.0875),(0.4,0.06),(0.5$, $0.0425),(0.6,0.03),(0.7,0.0125),(0.8,0.01),(0.9,0.005),(1,0.0025)$

NAVY_PERSONNEL_REVENUE = GRAPH (WELFARE.SALARY $/ 2$ )

$(0.00,0.08),(0.1,0.13),(0.2,0.185),(0.3,0.26),(0.4,0.37),(0.5,0.45)$, $(0.6,0.495),(0.7,0.525),(0.8,0.575),(0.9,0.655),(1,0.995)$

The policy scenario and model simulation: The next step is to develop a policy scenario in the performance evaluation system model of performance allowance. These policy scenarios as follows.

Scenario 1: On the welfare aspect, the professional income enhancement policy for Navy personnel. This policy is carried out gradually every year for inflation and include it in the performance allowance structure. Furthermore, this scenario runs on the model and will see its impact on the welfare aspect of the Navy personnel and its effect on the performance allowance system. The objective is to obtain a policy evaluation score which is an indicator of the evaluation of the policy parameters. Another goal is to get a score or index on the Navy personnel welfare aspect along with all the criteria that have a significant effect on the performance allowance system. The score is an indicator for a comprehensive evaluation of the performance allowance system within the Navy.

Scenario 2: On the state and public service aspect, the workload improvement policy that impacts on the increased risk of assignment. This policy is focused on 


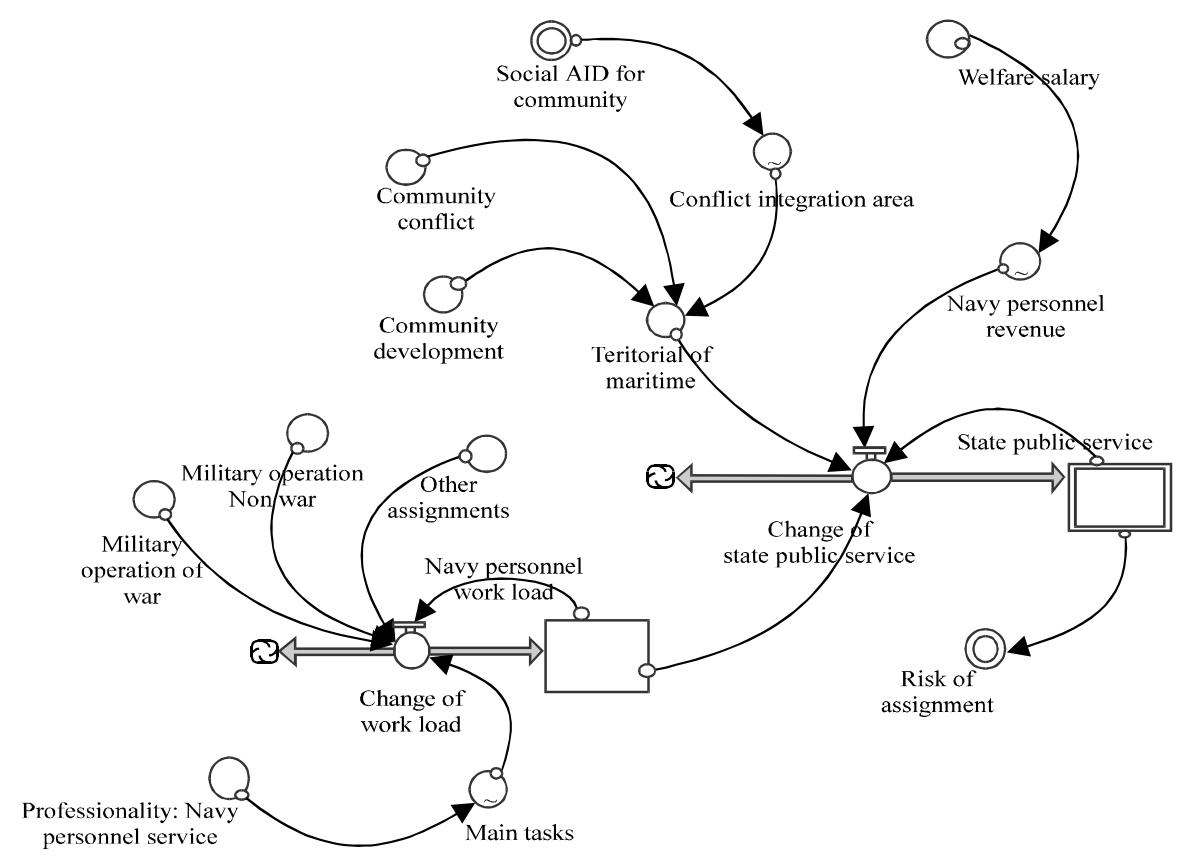

Fig. 7: Stock and flow diagram of the state and public service Navy personnel aspects

the work or tasks of Navy personnel who are at high risk. This research is usually done by special soldiers of Navy personnel. This scenario is done with the aim to know the impact and influence of workload variable and the risk of assignment to the performance value of Navy personnel as a system. Increased workloads based on special expertise or advanced expertise that will professionally affect the risk of assignment which in turn may impact the performance allowances of Navy personnel.

Furthermore, a model simulation was conducted to obtain a policy evaluation score which is an indicator of the evaluation parameters of the Navy personnel allowance system. In addition to get the value or score on the aspect of state public service and all the criteria that have a significant effect on performance allowance system. The score is an indicator for evaluation. The following Fig. 8 is a graph of the simulation results on the performance allowances evaluation model on the Navy personnel welfare aspects and state and public service aspects.

Figure 8 shows the relationship between professional income, social status and welfare values of Navy personnel. Figure 9 shows the relationship between workload, the risk of assignment and the value of state and public service of Navy personnel.

In Fig. 8, relationships graph of professional income, social status and personnel welfare, it can be analyzed that the three variables have a significant linear relationship, it's meaning that the higher of the value of professional income the higher the impact on improving social status of Navy personnel and the higher as well as its impact on improving the welfare aspect of Navy personnel. The Navy personnel welfare aspect is also strongly influenced by performance allowance variables as a system that interacts. The evaluation score obtained on the aspect of Navy personnel welfare are as follows:

- Evaluation score of performance allowance: 8.31 (high: warning)

- Evaluation score of personnel welfare aspect: 8.20 (high; warning)

- Evaluation score of Navy professional income: 7, 51 (high; warning)

- Evaluation score of social status: 6.09 (medium; moderate)

In Fig. 9, relationships graph of workload, risk assignment and state public services, it can be analyzed that if the scenario increasing the workload of Navy soldiers performed then it will have a significant impact on the risk of assignment. At the time of workload increased gradually per year then the risk of assignment will also rise, similarly, the value of state and public service aspects will also go up, meaning that the variable workload of Navy personnel soldiers significantly affects both aspects and variables.

Furthermore, it can be analyzed also that the increase performance allowance of the Navy personnel will also 


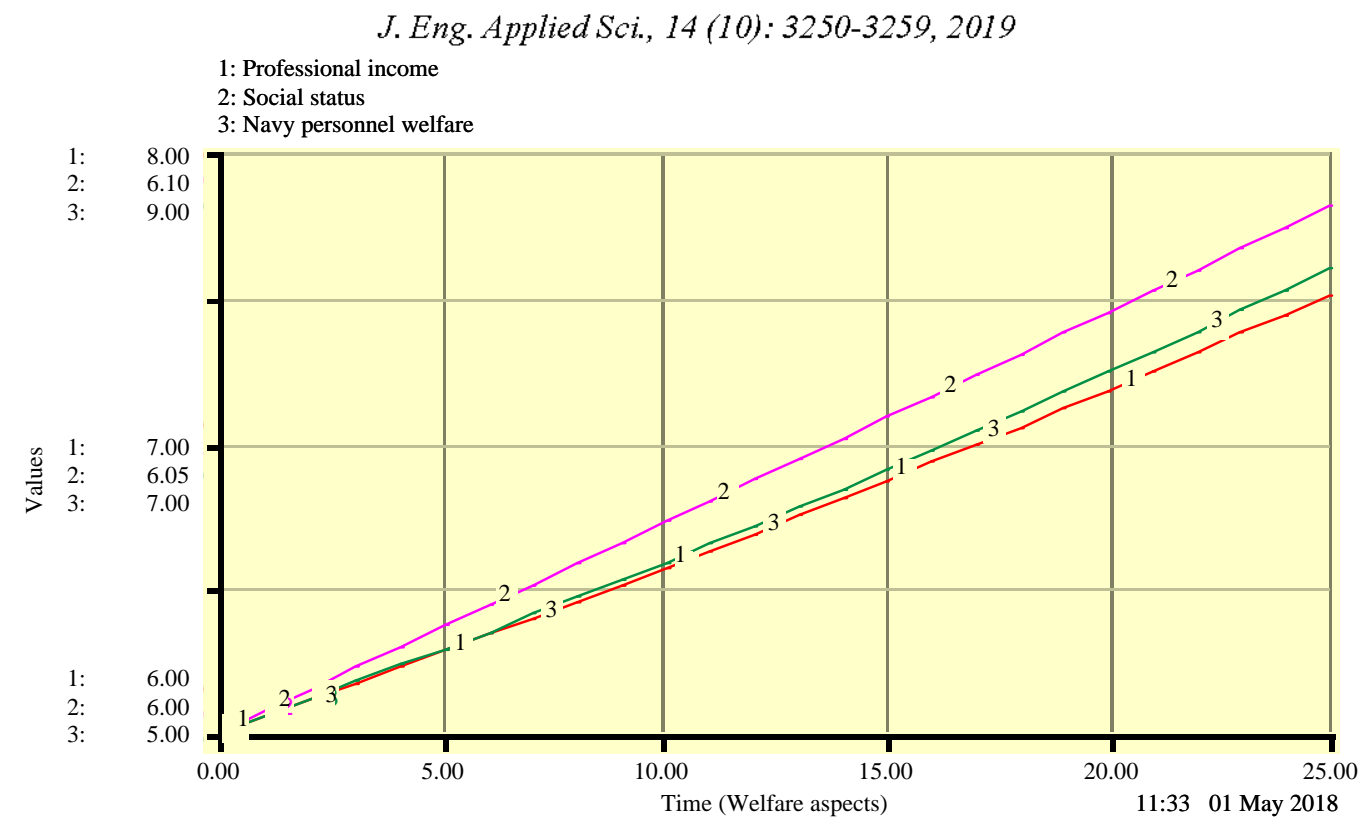

Fig. 8: Relationship graph of professional income, social status and personnel welfare

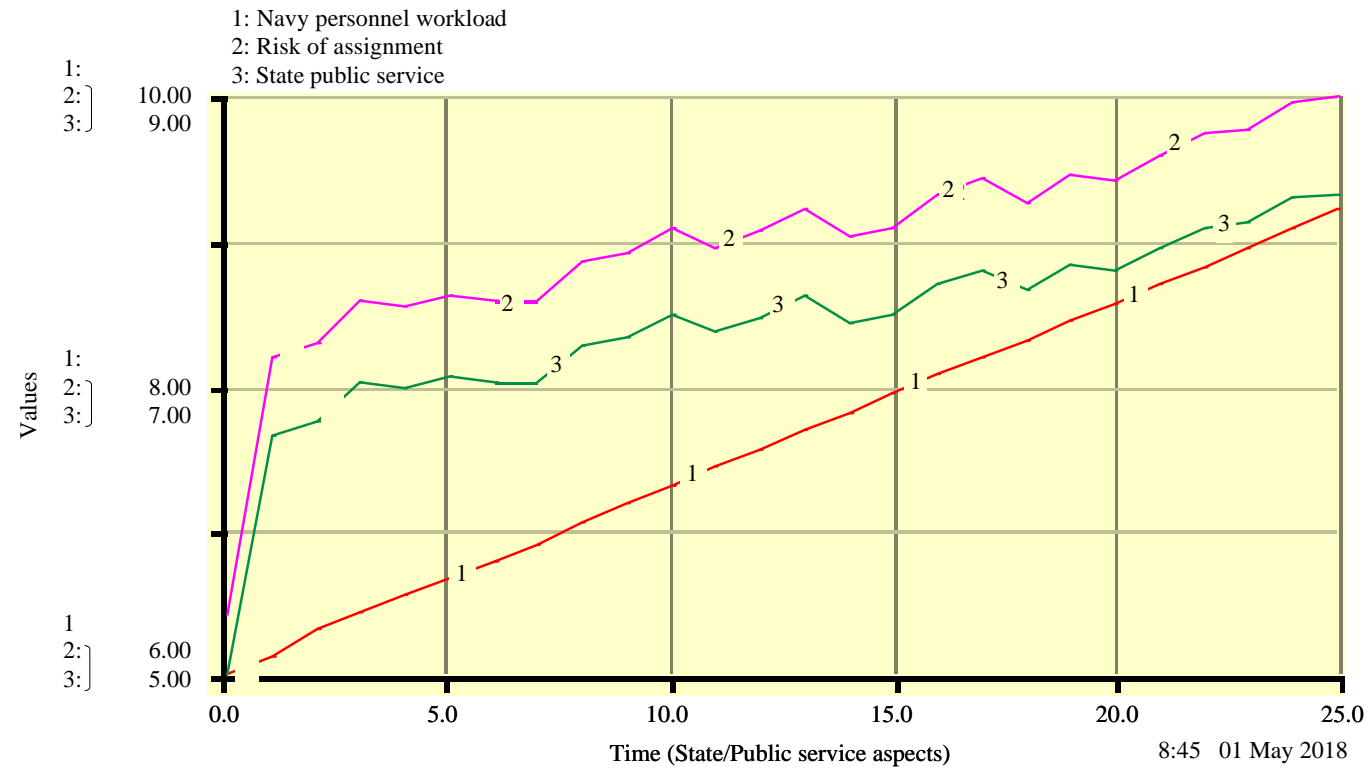

Fig. 9: Relationship graph of workload, risk of assignment and state public services

affect the rise of state and public service aspects of Navy personnel. This can be seen in the evaluation modeling results if it is simulated then the state public service aspect variable that has the key variable "workload" will have an impact on the Navy personnel of risk assignment variable which then the variable will move the increased value on the aspect of public service to the country. The evaluation scores obtained on the aspects of state public services are as follows:

- Evaluation score of performance allowance: 8.31 (high; warning)
- Evaluation score of state and public service: 8.32 (high; warning)

- Evaluation score of Navy personnel workload: 9.22 (very high; alert)

- Evaluation score, risk of assignment: 8.99 (high; warning)

\section{CONCLUSION}

The aspect of the welfare of Navy personnel and the aspect of state public service of Navy personnel is an aspect which significantly affecting the performance 
allowance policy provided to Navy Personnel. In this research, the model for policy evaluationon welfare and state-public service aspect of Navy personnel has been done with system dynamic system. Modeling of system dynamics is a model that describes the interaction of all aspects and criteria that influence of the evaluation performance allowances system, especially, on the welfare aspect and state public service of Navy personnel. This evaluation model generates evaluation scores based on dimensions of aspects, criteria and time. The score is an indicator of the importance of a policy which represents the policy being run or not and to determine which variables are most significantly influential.

The simulated of scenario policy 1 is "Increased of Navy Professional Income". The gradual increase is done annually by inflation and incorporates the value of professional income into the performance allowances structure of the Navy personnel. The analysis and evaluation are done thoroughly in the scenario and generates the evaluation score of the variables. The next simulated of scenario Policy 2 is "Workload improvement policy that impacts on increasing risk of assignment. The analysis and evaluation are done thoroughly in the scenario and generates the evaluation score of the variables

\section{RECOMMENDATIONS}

Based on the model evaluation result, it is found that the policy of increasing professional allowance and the policy of increasing the workload of the Navy personnel has a significant impact on the performance of Navy personnel which further improves the welfare aspect and the state public service aspect. So, in the end, this policy scenario must be programmed and executed to achieve the desired professionalism of the troops as a necessity to increase the performance allowance of the Navy personnel.

\section{ACKNOWLEDGEMENTS}

The resaerchers greatly acknowledge the support from Jakarta State University (UNJ), Esa Unggul University and Indonesian Navy Institution for providing necessary resources to carry out this research work. The researchers are also grateful to the anonymous reviewers and journal editorial board for their many insightful comments which have significantly improved this study.

\section{REFERENCES}

Ahmadi, A., O.S. Suharyo, K. Susilo and P. Pratisna, 2017. Applied of impressed current cathodic protection design for fuel pipeline network at aaval base. Iran. J. Mater. Sci. Eng., 14: 41-52.
Bryson, J.M., 1995. Strategic Planning for Public and Nonprofit Organization: A Guide to Strengthening and Sustaining Organizational Achievement. Jossey-Bass, SanFrancisco, California, USA., ISBN: 9780787901417 , Pages: 325.

Forrester, J.W., 1997. Building a system dynamics model. Master Thesis, Massachusetts Institute of Technology, Cambridge, Massachusetts.

Hasenfeld, Y., 1983. Human Service Organizations. Prentice Hall, Upper Saddle River, New Jersey, USA., ISBN: 9780134474908 , Pages: 276.

Imurana, B., R.H. Kilu and A.B. Kofi, 2014. The politics of public policy and problems of implementation in Africa: An appraisal of Ghana's national health insurance scheme in $\mathrm{Ga}$ East District. Intl. J. Humanities Soc. Sci., 4: 196-207.

Martinez-Moyano, I.J., E. Rich, S. Conrad, D.F. Andersen and T.R. Stewart, 2008. A behavioral theory of insider-threat risks: A system dynamics approach. ACM. Trans. Model. Comput. Simul., 18: $1-27$.

Muhammad, F., 2014. Leadership, governance and public policy implementation competencies in the broader public sector. Eur. J. Bus. Manage., 6: 66-73.

Sandfort, J., 1999. The structural impediments to human service collaboration: Examining welfare reform at the front lines. Soc. Serv. Rev., 73: 314-339.

Sterman, J.D., 2000. Business Dynamics: Systems Thinking and Modeling for a Complex World. Irwin/McGraw-Hill, Boston, Massachusetts, USA., ISBN:978-0-07-231135-8, Pages: 982.

Suharyo O.S., D. Manfaat and H.D. Armono, 2017. Establishing the location of naval base using fuzzy MCDM and covering technique methods: A case study. Intl. J. Oper. Quant. Manage., 23: 61-87.

Sundarakani, B., A. Sikdar and S. Balasubramanian, 2014. System dynamics-based modelling and analysis of greening the construction industry supply chain. Intl. J. Logistics Syst. Manage., 18: 517-537.

Thornhill, C., 2009. Local governments contribution to a sustainable developmental state. Administratio Publ., 17: 25-44.

Tsolakis, N. and J.S. Srai, 2017. A system dynamics approach to food security through smallholder farming in the UK. Chem. Eng. Trans., 57: 2023-2028.

Youssefi, H., V.S. Nahaei and J. Nematian, 2011. A new method for modeling system dynamics by fuzzy logic: Modeling of research and development in the national system of innovation. J. Math. Comput. Sci., 2: $88-99$ 